\title{
Parent Reading Belief Inventory: adaption and psychometric properties with a sample of Greek parents
}

\author{
Chrysoula Tsirmpa*, Nektarios Stellakis**, Konstantinos Lavidas*** \\ *University of Patras; tsirmpa.chrysoula@hotmail.com \\ **University of Patras; nekstel@upatras.gr \\ ***University of Patras; lavidas@upatras.gr
}

\begin{abstract}
In recent years, the importance of parents' beliefs in their children's literacy has increasingly been recognized. The main purpose of this article is to investigate: a) the internal consistency of the 7 subscales of the PRBI, b) the factor structure and c) the concurrent validity in a sample of Greek parents. In this survey 168 parents of preschool children attending the 13 public kindergartens in the city of Pyrgos, during the school year 2017-2018 participated. Six of the seven subscales of PRBI demonstrated adequate internal consistency. Principal component and parallel analyses revealed a four-factor structure and preliminary evidence of concurrent validity was also revealed. On the basis of the results, PRBI is considered an appropriate tool for investigating the beliefs of parents in Greece as well. The evidence shows the continuation of the research to a wider sample for the definition of the factor structure tool on Greek specimen.
\end{abstract}

Keywords: parents' beliefs, home literacy practices, PRBI, psychometric properties

\section{Introduction}

Children's literacy according to new perceptions, begins from the moment of birth and is influenced and enhanced by the experiences they take in the family and the wider social environment. It's developed and conquered naturally in the family environment and is based on everyday experience and knowledge. This is a non-formal learning that happens spontaneously through reactions with the environment and adults and its main means is oral speech. It includes a wider range of behaviors, related to learning reading and writing but they occur much before the child's entrance to elementary school and the learning of reading in the conventional way (Clay 1966, Teale \& Sulzby 1986, 1989, Whitehurst \& Lonigan 1998). As children are actively engaged in using language to read and write and to explore print in their play, they learn how written language works. When children have opportunities to participate in meaningful literacy activities in supportive literacy-conscious environments, they refine their understanding and knowledge of print. Therefore, long before children attend school and take part in formal lessons to learn to read and write, they already know what written language can be about, who communicates with writing, and some of the ways this is done (De Silva \& Feez 2015). According to surveys, in almost every family, there are reading and writing activities, irrespective of nationality, race, social class, educational level or the parents' financial status (Teale 1986, Purcell-Gates 1996, Battle 2009). Although almost all families are given opportunities for reading and writing during their daily routine, the quality of these activities varies according to the family environment (Battle 2009). Important factors related to the quality of these activities are among other things parents' beliefs about literacy (Mullis et al. 2012). In Greece, only a few small-scale surveys have been carried out related to family literacy beliefs and how these are related with the home literacy practices (Kardasi 2014, Melesanaki 2014), and to the authors' knowledge, no attempts have been made to look into psychometric measures of the Parent Reading Belief Inventory (PRBI). The current research will cover the relevant research gap and will help us to understand families' cultural models that will serve as the foundations for competent collaborations between early childhood educators and families.

\section{Parents' literacy beliefs}

The meaning of beliefs is a multidimensional meaning that is difficult to define. In this research, as in many others related to literacy, parents' beliefs are related to established and socially constructed conceptions regarding literacy and the way someone becomes literate (Weigel et al. 2006). Parents' beliefs develop according to social culture, parents' personal experiences and the unique interactive relationship between parents and children. They are connected to child-rearing goals, child 
development in general and the role that parents (need to) play in child development (Rowe \& Cassilas 2010). Moreover, they influence the methods the parents follow and the children's motives for reading (Sigel \& McGillicuddy-DeLisi 2002, Lynch et al. 2006, Rowe \& Casillas 2010, Baker \& Scher 2010).

Previous important approaches have shown that some parents believe they need to play an active role to the children's literacy skills development, while others believe that it is the school's responsibility to teach children writing and reading. Similarly, whereas some parents believe that creating a rich, stimulating environment is important to their children's development, others may not (Stone et al. 2014). In addition, in the cases that the parents regard reading as a pleasant activity and have a more active role in the literacy skills development, children show more interest for reading, have more knowledge about writing and score better results at school (DeBaryshe \& Binder 1994, Sonnenschein et al. 2000, Weigel et al. 2006).

Sonnenschein et al. (1997) researched the beliefs of preschoolers' parents, in relation to how they consider children learn to read more efficiently and found out that they could categorize the parents' beliefs in two groups: (a) those that highlight the reading "skills" and that need to be taught to children and (b) those that highlight the "entertainment" through reading. Evans et al. (2004), in corresponding research referred to two main approaches regarding the different parents' beliefs: (a) the "graphophonemic" or "bottom-up" approach and (b) the "constructivist" or "top-down" approach. Based on the first approach, parents paid attention mostly in gaining literacy skills, such as phonological awareness and the knowledge of letters and words, whilst in the second approach parents paid more attention to reading comprehension. Weigel et al. (2006) researched as well, preschoolers' mothers' beliefs and discovered that they could categorize the mothers in two groups: the "Facilitative" and the "Conventional". The first category's mothers had a more active role in their children's literacy development, contrary to the second group's mothers, who believed they couldn't do much for their children and considered literacy development more of a school project.

\section{Literacy beliefs of Greek parents}

Knowing parents' literacy beliefs may be an important key to understanding the differences in Greek children's literacy experiences at home and school. Unfortunately, in Greece, only a few small-scale surveys have been carried out related to family literacy beliefs and there is a need for further research. In Greece, all of the parents give great importance to children's literacy development, because they believe that this will help them to succeed at school and in their lives. However, there are differences in parents' attitudes and behaviors towards literacy, which are related particularly, to the socio-economic and educational level of the parents. The parents, with a higher socio-economic and educational level view literacy development more as entertainment and less as acquiring skills. These parents have great aspirations for their children, they involve their children mainly in informal literacy practices, have children who love reading and the books are part of everyday life. On the other hand, parents of middle and lower educational and socio-economic background have traditional views and are more involved in direct literacy activities. These parents don't believe in their self-efficacy, because they feel they are not capable, or because they think that teachers more than parents are responsible for literacy development and the need information about the ways for enhancing children's literacy development. In addition, the sex affects the involvement of parents in everyday literacy activities and in kindergarten, with the mothers being more involved than fathers (Kardasi 2014, Melesanaki 2014).

\section{Parent Reading Belief Inventory (PRBI)}

The investigation of parents' beliefs about literacy concerned and keeps concerning to the present day researchers who want to see how parents' beliefs are connected with the practices they follow. The development of PRBI is one of the first efforts to plan a valid and reliable tool to research the parents' beliefs and their possible connection with the practices they follow in the family. DeBaryshe and Binder (1994) designed this instrument to assess attitudes about what and how children learn from reading as well as parents' beliefs about their role as teachers of their children. 42 items are organized in seven subscales and parents indicate the extent to which they endorse each item on a 4-point Likert scale 
(1=strongly disagree to $4=$ strongly agree). The names and content of the scales are as follows: (1) Teaching Efficacy (items1-9): views on parents' role as teachers of school-related skills; (2) Positive Affect (items10-20): positive affect associated with reading; (3) Verbal Participation (items 20-27): the value placed on children's active verbal participation when reading; (4) Reading Instruction (items 2831): the appropriateness of direct reading instruction; (5) Knowledge Base (items 32-36): whether children acquire moral orientations or practical knowledge from books; (6) Resources (items37-40): whether limited resources are an obstacle to reading; (7) Environmental Input (items 41-42): the malleability of language development.

DeBaryshe and Binder (1994) distributed the questionnaire to 155 Afro-American and Euroamerican parents of children aged 2-5 years old, of low financial status and found a strong connection between beliefs and practices. Through the data analysis, the researchers discovered that the beliefs predicted the literacy practices mothers'-children's along with the children's interest in books. The researchers developed the items so that a high score reflects beliefs that parents are important teachers, children should be active participants during shared book reading, the goals of reading are enjoyment, knowledge and oral language development rather than direct reading instruction, limited resources should prevent parents from reading with their children and language development is influenced by environmental stimulation. In addition, the reported reliability and validity rates were satisfactory. In particular, regarding the internal consistency of seven subscales, the rates Cronbach's alpha ranged from .50 to .85 and only in two (Reading Instruction and Environmental Input), the internal consistency rates were below 70 (DeBaryshe \& Binder 1994).

\section{Previous research approaches about the adaption of PRBI}

In many researches abroad, PRBI has been applied and used, in order to research the relationship between the parents' beliefs and the results they have on children, since it has been proved that they affect the child's development and its school course. However, the minimum study efforts of the tool's psychometric properties did not show adequate findings regarding the confirmation of the seven subscales as they are suggested by the tool's creators. Only minimum proof was found for the reliability of most of the seven subscales.

In particular Gonzalez et al. (2013), wanted to research to what extent PRBI measures parents' beliefs. Their sample consisted of 136 Latino and Afro-American parents who had preschool age children. In this research there were evaluations of internal consistency similar to those referred by the creators ranging from 0.68 to 0.83 . Using the Confirmatory Factor Analysis (CFA) separately for each of the seven subscales, revealed an adequate fit for only two of the seven subscales (Reading Instruction and Resources). Similarly Radisic and Seva (2013) adjusted the PRBI in Serbia, using a sample of 227 parents from different municipalities of Belgrade whose children attended public kindergartens. The researchers taking into consideration the theoretical underpinnings of PRBI of seven subscales estimated alphas coefficients ranged from .50 to .77 that were not fully comparable with the original values reported by the authors of the PRBI. Furthermore, the researchers found out that the initial structure of the seven subscales (theoretical underpinnings of PRBI) through Confirmatory Factor Analysis (CFA) is not confirmed since it appears poor fit keeping in mind the various fit coefficients that were used and mostly the coefficient Comparative Fit Index $(\mathrm{CFI}<0,7)$ that refers to the difference between the observed and predicted data.

The investigation of the factorial structure through the Exploratory Factor Analysis revealed structure up to five factors. In particular, structure of two factors that explain $54.6 \%$ of the variation excluding only four items revealed the Principal Component Analysis of PRBI that occurred to a sample of 77 Dutch participants (Boomstra et al. 2012). Moreover, the internal consistency (Cronbach's alpha) research showed similar rates to those of PRBI creators, except one subscale (Environmental Input) that was reported very low Cronbach's alpha. The Principal Component Analysis of PRBI showed a five factor structure excluding eight items that Wu and Honig (2010) accomplished in a sample of 731 mothers of preschoolers, in public and private schools in Taiwan. The researchers used PRBI in combination with Family Information Survey. The five subscales are: Knowledge Base, Verbal Participation, Positive Affect, 
Teaching Efficacy and Reading Instruction. Alpha coefficients were adequate ranging from .63 to .90. Finally, structure of a factor was revealed by the Rodriguez et al. (2009) analysis. These researchers investigated the Mexican-American parents' beliefs using PRBI coupled with Home Literacy Activities Questionnaire. In the research 274 preschoolers' parents, with low income and from an urban area southwest of USA took part. Principal Component Analysis (PCA) and Parallel Analysis revealed one factor structure. All the questions in the questionnaire were able to form only one factor that was explaining only the $55.3 \%$ of total variance. Moreover, concurrent validity was examined with the tool Home Literacy Activities Questionnaire revealed small $(|r|<0.36)$ relationships between literacy beliefs and home literacy practices.

Findings only for the reliability of the range were found and in the researches of Dhima (2015) and Husain et al. (2011). Specifically, in the research that took place in Albania, through a sample of 265 Albanian preschoolers' parents (Dhima 2015), were confirmed the reliability of the creators' factors in most of the seven subscales and only the Reading Instruction subscale had an adequate Cronbach's alpha. Similarly, in Husain et al. (2011) research PRBI was filled in from 72 mothers in Malaysia, with children aged 4-6 years old. In this research is shown only one very satisfactory factor of internal coherence Cronbach's alpha $=0.92$, of all the statements of the tool.

Lastly, the most recent work that is-to our knowledge-available has been done in Turkey by Iflazoglu Saban, Altinkamis and Deretarla Gul (2018). The researchers investigated Turkish parents' early literacy beliefs through the PRBI and tested the validity and reliability of the Turkish PRBI, as well. The PRBI was, in fact, adapted to Turkish by Turkay and Iflazoglu Saban (2011) and Simsek Cetin et al. (2014) but as the adaptation studies presented different results, a new study was needed to overcome the weakness in the previous studies. The new study was conducted in the central districts of Adana, a city in southern Turkey and 952 parents with children aged between 3-7 years old, participated. The researches utilized the PRBI, in combination with the Home Literacy Inventory (HLI), the Child Literacy Behaviours (CLB) and the Personal Information Form that they had prepared. The Cronbach Alpha reliability coefficient values ranged from .48 and .87 and were not entirely compatible with the original values as stated by the authors of the PRBI. The confirmatory factor analysis indicated that a seven-factor structure in the original form of the PRBI was validated, excluding three items that did not have significant t-values. In conclusion, considering the values from both confirmatory factor analysis and reliability analysis, the PRBI is considered a valid and reliable tool to investigate parents' literacy beliefs in Turkey (Iflazoglu Saban et al. 2018).

\section{Research objectives}

Although the PRBI is considered a useful tool for investigating parents' beliefs about literacy, satisfactory empirical findings for reliability and validity of a specific factor structure of many subscales to all former researches, don't exist. The purpose of this research is to examine:

a) the internal consistency of seven subscales of PRBI;

b) the factors structure of the instrument;

c) the concurrent validity of PRBI.

\section{Method \\ Participants}

In this survey only parents of children-aged 5 years old- attending public kindergarten in the city of Pyrgos, in Greece, during the school year 2017 - 2018 participated. The city of Pyrgos has 14 kindergarten schools, but the survey was carried out only on 13 , because in one kindergarten the students are Roma so it was excluded from the beginning because of the different cultural status these parents have. Moreover, because of the different cultural status also parents from other countries were excluded even though their children attend the 13 kindergarten schools, because our purpose was to investigate only Greek parents' beliefs. Sampling was "convenient" on the basis of physical proximity to the researcher. The total number of parents of Greek descent from the 13 kindergartens was 188, but 168 parents responded to the research. However, 15 parents' responses were excluded from our 
analysis due to missing values (at least 10 out of 42 items). Additionally, 6 parents' responses have not been taken into account, as they were multivariate outliers with critical values far beyond the Mahalanobis distance (Tabachnick \& Fidell 2007). So, the final sample included 147 parents, out of which the $89.8 \%$ were mothers and $10.2 \%$ fathers. Regarding their marital status, the highest percentage of parents (92.5\%) was married and had 2 children (56.6\%). 52.4\% of the parents had a girl attending the kindergarten and $44.9 \%$ a boy. As far as the age of parents is concerned, most of the fathers were 41 plus (50.4\%), while the mothers were between 36-40 years old. On the educational level of the parents, the highest percentage in both cases was at least high school graduates, $45.9 \%$ fathers and $47.9 \%$ mothers.

\section{Materials}

The research instruments that were used in this research are (a) the "Parent Reading Belief Inventory" (PRBI), (DeBaryshe \& Binder 1994), that is about the parents' beliefs and the importance of the reading in kindergarten children (it was shown in detail in paragraph "Parent Reading Belief Inventory, PRBI") and (b) the adaption of Grover J. Whitehurst's "Stony Brook Family Reading Survey (SBFRS)", modified by Weigel et al. (2006) and is about home literacy practices.

The adaption of the SBFRS, by Weigel et al. (2006) was to assess literacy and language activities at home with 79 mothers and their children in the USA. This particular survey includes 15 questions and refers to how often literacy practices take place in the family environment. More specific, questions 1-2, 5-9 and 12 refer to the literacy experiences, which are a result of the constant parents-children interaction, questions 3-4 and 10-11 to the experiences that discover and develop children on their own and questions 13-15 refer to the parents' personal reading habits, which work as literacy role models to the children. This instrument as criterion measure will allow us to support the concurrent validity of PRBI.

In order to use these two instruments we asked permission from their creators. Before using these two instruments we used adaptation that included a two-stage procedure: a) Translation check. Initially the surveys were handed to two English teachers to translate first from English to Greek and after three days, so there won't be a memory effect from Greek to English (Johnson 1998). After checking both publications there were no important differences in translation. The small differences concerned some words or phrases, which were accordingly modified so the statement is more comprehensible (i.e. "like" changed to "as", "they like to speak" turned into "they are great speakers", a sentence that was in plural number changed to singular and in two cases words were added to emphasize more the meaning of the sentence). Afterwards, the modified surveys were given to 15 parents who had certified good use of the English language and they were asked to answer first the English one and after one week the Greek, intending to see if the two instruments as they are distinguished in the two languages English (authentic) and Greek measure the same way. From the similarity check in these two different publications the match reached 90\% (Johnson 1998). After the translation procedure, a cultural adaptation of the questionnaire was need. This process was carried out in order to identify any areas presenting linguistic problems and to assess the respondent's level of understanding with the purpose of revealing inappropriate items and translation alternatives. The questionnaire was administered to five parents of preschool children, and after completing the questionnaire participants gave their general impression on the clarity of the items, the relevance of the content to their situation, the comprehensiveness of the instructions and their ability to complete it on their own. All of the parents admitted that everything was understandable and there was no difficulty to complete the questionnaire. b) Test-retest reliability meaning to what extent the answers repeated themselves the same way from the same people in two different measurements. In particular, we gave the surveys to fill in to 15 parents and a week later, so there is no memory effect, the same parents filled in the survey again. From checking the answers of the individuals before and after we discovered satisfactory reliability test-retest since the matching touched $85 \%$ (Franzen 2013). 


\section{Procedure}

Having the approval and permission from the Ministry of Education, Research and Religious Affairs, the kindergarten teachers were informed for the purpose and the procedure of the research in order to arrange group meetings in school with the parents whose children attended the respective kindergartens. Kindergarten teachers organized face-to-face survey sessions with the parents, in the school place, during which the parents were informed by the researcher, for the purposes of the research, signed their agreement and filed in the two surveys (PRBI and SBFRS). In case the parents did not attend, a second meeting took place in school. However, when they couldn't attend at all, the kindergarten teachers would give the surveys to be filled in at home, accompanied by a document with all the relevant to the research information. The parents returned them and handed them in a sealed envelope at the kindergarten and later the teacher would give the envelope to the researcher.

\section{Data analysis}

We initially investigated the reliability of the PRBI scale by counting the internal coefficients (Cronbach's alpha) of seven subscales of PRBI. Cronbach's alpha coefficients close to 0.7 are considered satisfactory (Cronbach 1951). Then to determine the extracted number of factors, we based on Horn's (1965) parallel analysis. Parallel analysis is considered the best method of extracting factors than KaiserGuttman rule (eigenvalues greater than one) and scree plot (keep the number of factors before the change of the slope). Scree plot and Kaiser-Guttman rule usually overestimate the number of factors and are prone to subjective bias (Jackson 1993). At parallel analysis, principal components analyses, was made using a simulation 1,000 random samples based on permutations of the actual data. We used permutations of the raw data set because some 42 items distributions showed a slight departure from normal distribution ( $O^{\prime}$ Connor 2000). The eigenvalues of the factors that turn out from the actual facts we compared with the 95th percentile eigenvalues from the simulation. When the eigenvalues of the actual data exceed the 95th percentile eigenvalues from the simulation, those factors can be considered actual factors in the dataset and therefore maintained in the final factorial structure. When the 95th percentile eigenvalues from the simulation are larger than the eigenvalues from the PCA you know that those factors probably are spurious (Wood, Akloubou Gnonhosou \& Bowling 2015). To extract the factorial structure of the overall fluctuation of parents' responses to 42 items of PRBI after the parallel analysis we performed a factor analysis with the method Principal Component Analysis. Details about this method will be discussed in the result section. Finally, in order to support the concurrent validity of PRBI, we test the correlations of the extracted factors with the statements of the literacy practices as measured by Stony Brook Family Reading Survey.

\section{Results}

\section{Reliability of the seven subscales of PRBI}

The factors of internal coherence Cronbach's alpha in the first six subscales according to the structure which is proposed by the creators (see Table 1) are considered satisfactory (Cronbach 1951) and almost similar to those that were figured by the instrument's creators.

Table 1: Cronbach's alpha of the PRBI by subscale.

\begin{tabular}{cccc}
\hline Subscales & Items & DeBaryshe \& Binder 1994 & Present study* \\
\hline Teaching Efficacy & $1-9$ & .73 & .70 \\
Positive Affect & $10-20$ & .85 & .83 \\
Verbal Participation & $20-27$ & .83 & .84 \\
Reading Instruction & $28-31$ & .63 & .64 \\
Knowledge Base & $32-36$ & .82 & .80 \\
Resources & $37-40$ & .79 & .88 \\
Environment Input & $41-42$ & .50 & .43 \\
\hline${ }^{*}$ To estimate the Cronbach's Alpha coefficients, we took into consideration the creators' suggestion to reverse the responses in 17 statements.
\end{tabular}




\section{The factorial structure of Parent Reading Belief Inventory (PRBI)}

Parallel analysis for the current study was run in SPSS (v. 24) utilizing a script developed by O'Connor (2000). A thousand datasets were generated based on permutations of the raw data, using a Principal Component Analysis method and the script produced eigenvalues from the actual data, mean eigenvalues and 95th percentile eigenvalues based on the random data sets. For the four first factors eigenvalues $(10.88,2.88,2.30$, and 2.17$)$ from the raw data are above the corresponding 95th percentile estimates created by the simulation. Simultaneously the slope of the generated scree plot (see Figure 1) indicates the cutoff for the number of four factors to extract from the factor analysis.

Figure 1: Screenplots of parallel analysis with 1000 random sample from actual data.

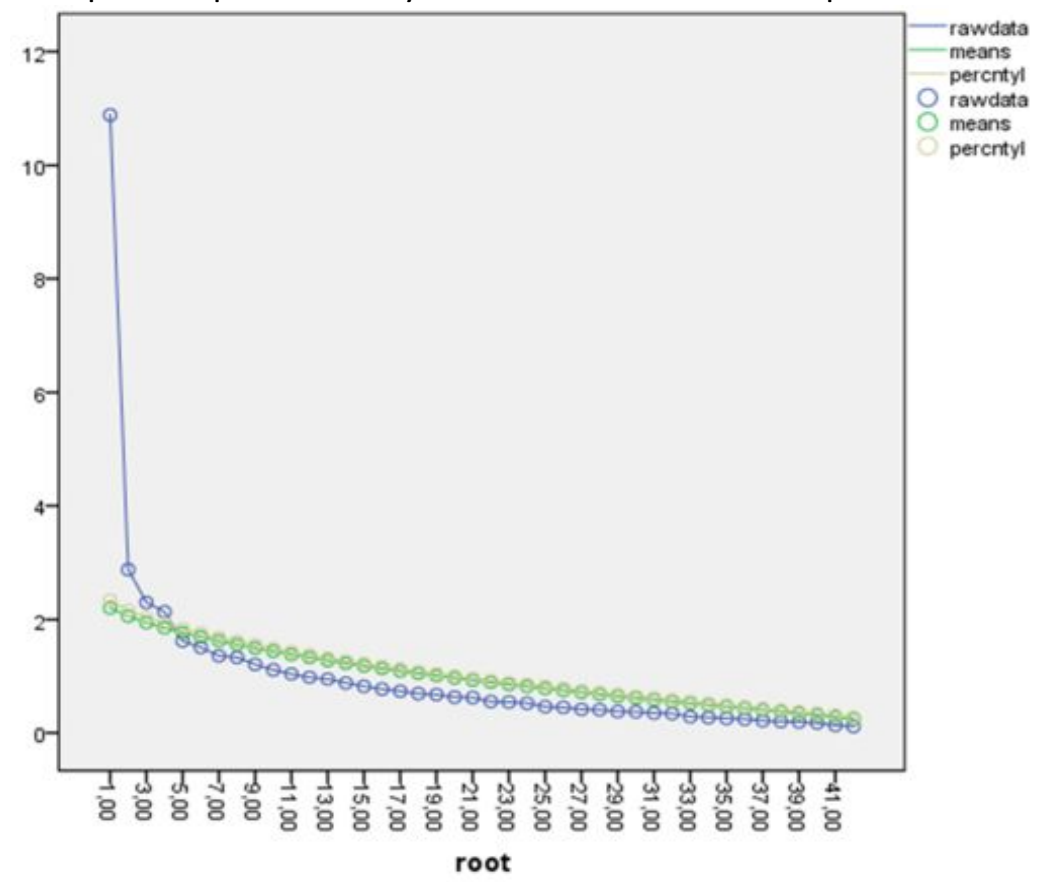

For the extraction of the factorial structure of the 42 items on four factors we exploited the method of Principal Component Analysis (Gorsuch 1983, Pett, Lackey \& Sullivan 2003). Not only the Bartlett's Test of Sphericity $(p<0.01)$ indicating that the correlation between the items is adequate for factor analysis but also the indices Kaiser-Meyer-Olkin $(\mathrm{KMO}=0,842) \mathrm{k \alpha}$ ( Measure Sample Adequacy (MSA at least 0.6 ) revealed that parents' answers define a satisfactory factorial structure. For the best distinction of the factorial structure oblique rotation was used and at the same time on factorial structure were included items with absolute loadings at least 0.4 (see Table 2). The oblique rotation was decided by taking into consideration the correlation (see Table 3) of extracted factors (Tabachnick \& Fidell 2007). The factorial structure of the four subscales even though it explains only the $43.34 \%$ of total variation is considered satisfactory since it indicates groups of similar semantic items. From the final structure 10 items were excluded $(1,3,4,5,10,13,15,18,41$ and 42) with low loadings ( $\mid$ loadings $\mid<0.4)$. The factorial structure of the four factors (subscales) differs from the structure the creators (DeBaryshe \& Binder 1994) of the seven factors suggest. The Cronbach's alpha coefficients, (see Table 2) we calculated for each factor showed satisfactory levels of internal consistency (Cronbach 1951). We also notice marginally adequate convergent validity of our factor structure since most loadings on every factor are in absolute value close to 0.7 . Respectively we notice satisfactory discriminant validity among the factors after there aren't noticed cross loadings of items among the four factors (Tabachnick \& Fidell 2007).

Table 2: Factors structure, loadings, communalities, extracted variance and Cronbach's alpha.

\begin{tabular}{cccccc}
\hline Items & F1 & F2 & F3 & F4 & Communalities \\
\hline 21 & .78 & & & .55 \\
33 & .77 & & & .64
\end{tabular}




\begin{tabular}{|c|c|c|c|c|c|}
\hline 35 & .77 & & & & .57 \\
\hline 22 & .73 & & & & .48 \\
\hline 23 & .73 & & & & .51 \\
\hline 34 & .69 & & & & .51 \\
\hline 36 & .63 & & & & .37 \\
\hline 27 & .59 & & & & .46 \\
\hline 26 & .58 & & & & .48 \\
\hline 20 & .53 & & & & .36 \\
\hline 25 & .47 & & & & .40 \\
\hline 24 & .45 & & & & .43 \\
\hline 17 & .44 & & & & .38 \\
\hline 32 & .40 & & & & .34 \\
\hline 30 & .40 & & & & .21 \\
\hline 37 & & .78 & & & .52 \\
\hline 40 & & .78 & & & .65 \\
\hline 38 & & .77 & & & .73 \\
\hline 39 & & .72 & & & .63 \\
\hline 16 & & .70 & & & .45 \\
\hline 14 & & .52 & & & .51 \\
\hline 19 & & -.66 & & & .43 \\
\hline 28 & & & .80 & & .61 \\
\hline 31 & & & .66 & & .48 \\
\hline 29 & & & .63 & & .38 \\
\hline 9 & & & .48 & & .45 \\
\hline 11 & & & .42 & & .37 \\
\hline 12 & & & .41 & & .37 \\
\hline 6 & & & & .70 & .46 \\
\hline 8 & & & & .66 & .45 \\
\hline 2 & & & & .60 & .40 \\
\hline 7 & & & & -.58 & .48 \\
\hline Variance & $25.91 \%$ & $6.85 \%$ & $5.48 \%$ & $5.08 \%$ & $43.33 \%$ \\
\hline $\begin{array}{c}\text { Cronbach's } \\
\text { alpha }\end{array}$ & .87 & .84 & .71 & .67 & \\
\hline
\end{tabular}

Taking into consideration the high loadings on every subscale, the four subscales, identify: F1) Knowledge Base (whether children acquire moral orientations or practical knowledge from books; F2) Resources (whether limited resources are an obstacle to reading); F3) Reading Instruction (the appropriateness of direct reading instruction) and F4) Teaching Efficacy (views on parents' role as teachers of school-related skills). Table 3 shows descriptive measures and correlations between factors. For the creation of the four variables, one for each factor, we calculated the average of respondents' answers for the items that belong to each factor, after reversing the respondents' answers to items 19 and 7. More specifically according to the parents' beliefs: a) high score on F1 (Knowledge Base) mean that children acquire more knowledge through reading; b) high score on F2 (Resources) mean that exist more obstacles on reading; c) high score on F3 (Reading Instruction) mean that parents get involved more to the reading procedure through several relevant practices and d) high score on F4 (Teaching Efficacy) mean that parents believe they don't play a significant role as their children's teachers. 
Table 3: Descriptive statistics and Pearson product correlations among factors.

\begin{tabular}{ccccccc}
\hline Factors & Mean & SD & F1 & F2 & F3 & F4 \\
F1 & 3.26 & .33 & 1 & & & \\
F2 & 1.69 & .42 & $-.51^{*}$ & 1 & 1 & \\
F3 & 3.01 & .39 & $.41^{*}$ & $-.27^{*}$ &. $.34^{*}$ & 1 \\
F4 & 2.06 & .47 & $-.35^{*}$ & $.25^{*}$ & &
\end{tabular}

Finally, we notice (see Table 4) satisfactory correlations to the four factors with the items of SBFRS scale that was used as criterion measure supporting the concurrent validity of PRBI. For example, taking into consideration the scores for every subscale of PRBI related to item 1 of SBFRS, that refers to the frequency of reading books to children, we would say that: The more the parents read to the children the more knowledge they acquire $\left(r=.41^{* *}\right)$, less obstacles exist on reading $\left(r=-.54^{* *}\right)$, more practices conveyed relevant to reading $\left(r=.16^{*}\right)$ and less parents believe they aren't important teachers for their child.

Table 4: Correlations among four factors of PRBI and SBFRS items.

\begin{tabular}{|c|c|c|c|c|}
\hline & $\begin{array}{c}\text { F1 } \\
\text { Knowledge Base }\end{array}$ & $\begin{array}{c}\text { F2 } \\
\text { Resources }\end{array}$ & $\begin{array}{c}\text { F3 } \\
\text { Reading Instruction }\end{array}$ & $\begin{array}{c}44 \\
\text { Teaching Efficac }\end{array}$ \\
\hline $\begin{array}{c}\text { SBFRS_1 } \\
\text { "How often do you or } \\
\text { another family member read } \\
\text { a picture book with your } \\
\text { child?" }\end{array}$ & $.41^{* *}$ & $-.54^{* *}$ & $.16^{*}$ & -.08 \\
\hline $\begin{array}{c}\text { SBFRS_2 } \\
\text { "How often does your child } \\
\text { ask to be read to?" } \\
\text { SBFRS } 3\end{array}$ & $.37^{* *}$ & $-.50^{* *}$ & $.25^{* *}$ & -.03 \\
\hline $\begin{array}{c}\text { "How often does your child } \\
\text { look at books by himself or } \\
\text { herself?" }\end{array}$ & $.23^{* *}$ & $-.28^{* *}$ & $.23^{* *}$ & .01 \\
\hline $\begin{array}{c}\text { SBFRS_4 } \\
\text { "How often does your child } \\
\text { draw pictures?" }\end{array}$ & .15. & -.11 & .12. & -.11 \\
\hline $\begin{array}{l}\text { SBFRS_5 } \\
\text { "How often do you or } \\
\text { another family member sing } \\
\text { or recite rhymes to your } \\
\text { child?" }\end{array}$ & $.20^{*}$ & -.14 & $.19^{*}$ & $-.22^{* *}$ \\
\hline $\begin{array}{c}\text { SBFRS_6 } \\
\text { "How often do you or } \\
\text { another family member tell } \\
\text { stories to your child?" } \\
\text { SBFRS } 7\end{array}$ & $.33^{* *}$ & $-.32^{* *}$ & $.28^{* *}$ & $-.24^{* *}$ \\
\hline $\begin{array}{l}\text { "How often do you or } \\
\text { another family member play } \\
\text { games with your child?" }\end{array}$ & $.19^{*}$ & $-.21^{* *}$ & .06 & .03 \\
\hline $\begin{array}{l}\text { "How many minutes did you } \\
\text { or another family member } \\
\text { read to your child } \\
\text { yesterday?" }\end{array}$ & $.17^{*}$ & $-.27^{* *}$ & $.24^{* *}$ & -.09 \\
\hline SBFRS_10 & $.35^{* *}$ & $-.28^{* *}$ & .04 & $-.23^{* *}$ \\
\hline
\end{tabular}




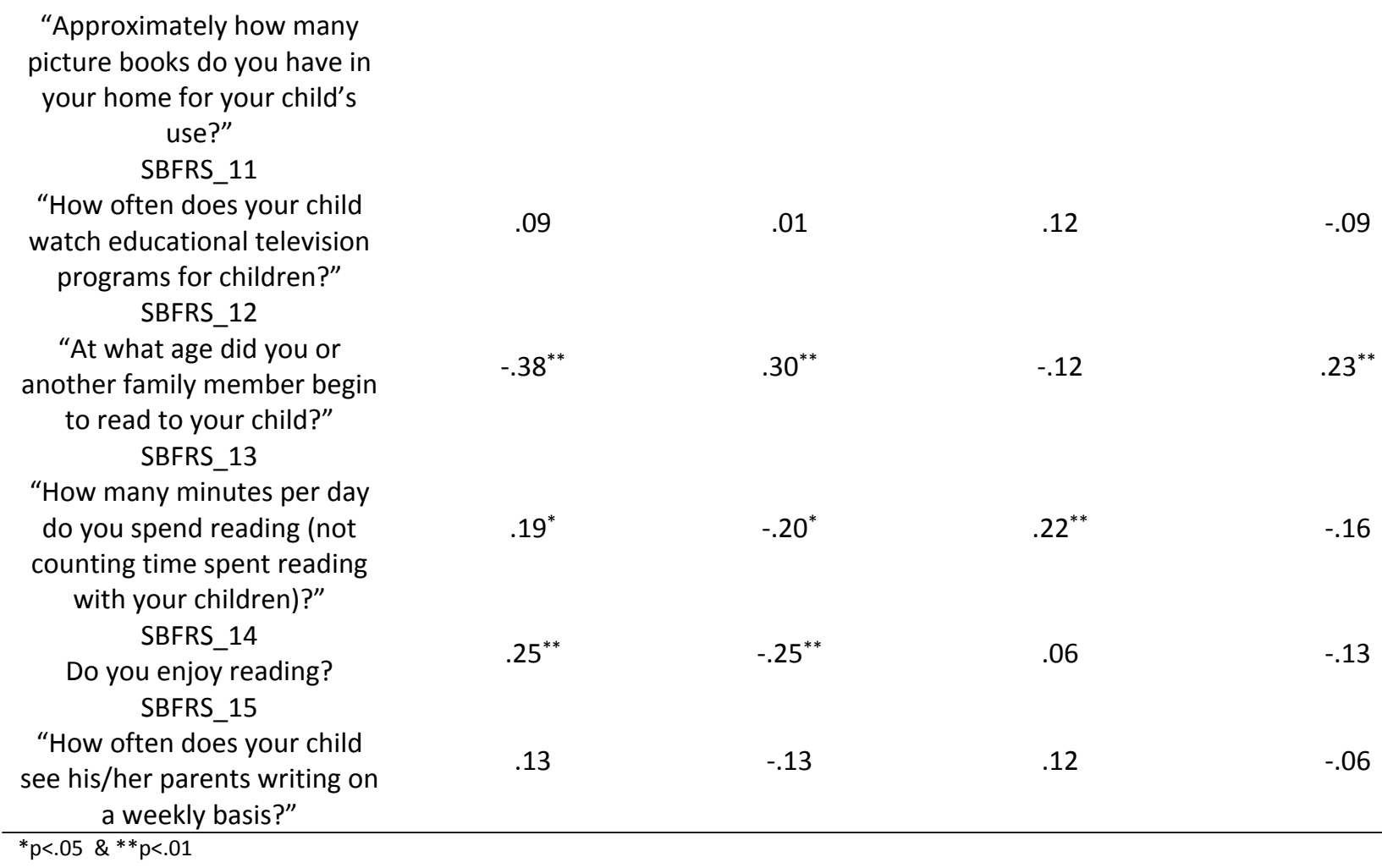

\section{Discussion}

The purpose of this article was to consider the internal consistency of seven subscales of PRBI, the factorial structure and the concurrent validity of the particular instrument, to a sample of Greek parents.

\section{Internal consistency}

Given to the sample of Greek parents involved in the survey, the Cronbach's alpha internal cohesion coefficients are consisted satisfactory and almost similar to those calculated by the PRBI's creators. More specifically, the estimates for internal consistency ranged from .64 to .88 for the six of the seven subscales (Teaching Efficacy, Positive Affect, Verbal Participation, Reading Instruction, Knowledge, Resource) and only for the last subscale (Environmental Input) we had low reliability. In low reliability on the particular subscale had ended up both Wu and Honig (2010) on sample from Taiwan and Boomstra et al. (2012) on sample from the Netherlands. Also low and unsatisfactory internal consistency values in this subscale as well as in other surveys carried out in other countries. More specifically in Mexico Rodriguez et al. (2009) found low reliability on Environmental Input and Reading Instruction subscales, in Albania, Dhima (2015) on subscales of Environmental Input, Reading Instruction and in Serbia, Radisic and Seva (2013), on Environmental Input, Resources, Teaching Efficacy subscales.

\section{Factorial structure}

Through this specific Exploratory Factor Analysis have emerged four factors (Knowledge Base, Resources, Reading Instruction, Teaching Efficacy) and 10 items with low loadings were excluded (1, 3, 4, $5,10,13,15,18,41$ and 42$)$. These items were overlapped by others that best reflected parents' literacy beliefs. The factorial structure of the four subscales although it only explains the $43.3 \%$ of the total variance is considered satisfactory since it indicates groups of similar semantic variables. The existing structure is characterized by a marginally acceptable converging validity of subscales but satisfactory discriminant validity between the subscales. With respect to the reliability check the coefficient of Cronbach's alpha calculated for the specific factor, showed satisfactory levels of internal consistency. A similar structure but with more factors revealed the surveys carried out in Taiwan and the Netherlands. More specifically, in Wu and Honig (2010) survey, the factor analysis resulted in the retention of 24 
items from the original PRBI scales, organized into five subscales (Knowledge Base, Verbal Participation, Positive Affect, Teaching Efficacy and Reading Instruction) with adequate alpha coefficient. Respectively, Boomstra et al. (2012) kept the seven subscales but with 38 items, excluding 6, 8 17, 41 in order to qualitatively evaluate these items.

\section{Concurrent validity}

Preliminary support for the concurrent validity of the PRBI was evidenced by its association with the frequency of mothers' and children's literacy practices. Our preliminary results coupled with Debaryshe and Binder's (1994) study, suggest that the relationship between parents' beliefs and practices begins to emerge when on examines domain-specific beliefs and directly relevant practices. In particular and with respect to the four subscales, we found satisfactory correlations between the subscales and the SBFRS items, which was used criterion measure.

\section{Implications and limitations}

On the basis of the above results, we could say that the PRBI, according to the factorial structure presented, is considered an appropriate tool for investigating the beliefs of parents in Greece as well. This fact comes to cover the gap that exists in methodological tools in our country and provides researchers, educators and specialists with a tool to explore parents' beliefs about literacy with satisfactory reliability and validity.

The survey was carried out on parents whose children attended public kindergartens in the city of Pyrgos, in Greece which is considered an urban area. However, this sample is not considered representative and the results cannot be generalized concerning the psychometric properties of PRBI. In addition to the survey, the majority of participants are mothers since they are more likely to come to kindergarten, so this way we cannot have evidence for the Greek fathers' beliefs. In a future survey we could address a larger sample of parents, including a larger percentage of fathers and research to be carried out in more regions of Greece, so that we can make a generalization of the results of the beliefs of Greek parents and the factorial structure of the PRBI, in a large scale.

Moreover, the research was done on parents of Greek origin, so we do not know what happens when a parent has a different background and how that affects his/her beliefs. In future research, parents could also be included, one of them having a different background, and see how the mother's and father's different origins affect beliefs and hence the literacy practices that they use. Consequently, future research should continue to empirically refine the PRBI construct by recognizing the multiple domains of influence.

It would be quite interesting if we wanted to deepen in parents' beliefs to combine quantitative and qualitative research and to complement the questionnaires to be combined with interviewing parents. The information collected could be used to guide the revision elimination and/ or addition of items and in this way, new and considerable elements can arise that will enhance validity and reliability of PRBI.

\section{References}

Baker, L. \& Scher, D. (2010). Beginning readers' motivation for reading in relation to parental belief and home reading experience. Reading Psychology, 23 (4), 239-269. doi: 10.1080/713775283.

Battle, D. E. (2009). Multiculturalism, language, and emergent literacy. In P. M. Rhyner (Ed.), Emergent literacy and language development (pp. 192-234). New York: The Guilford Press.

Boomstra, N., Van Dijk, M., Jorna, R. \& Van Geert, P. (2012). Parent reading beliefs and parenting goals of Netherlands Antillean and Dutch mothers in Netherlands. Early Child Development and Care, 183 (11), 16051624. doi: $10.1080 / 03004430.2012 .744005$.

Clay, M. (1966). Emergent Reading Behavior. Unpublished Doctoral Dissertation. New Zealand: University of Auckland.

Cronbach, L. J. (1951). Coefficient alpha and the internal structure of tests. Psychometrika, 16 (3) 297334. doi:10.1007/bf02310555.

DeBaryshe, B. D. \& Binder, J. C. (1994). Development of an Instrument for Measuring Parental Beliefs about Reading Aloud To Young Children. Perceptual and Motor Skills, 78, 1303-1311.

De Silva, J. \& Feez, S., (2015). Exploring literacies: Theory, Research and Practice. New York: Palgrave Macmillan. 
Dhima, S. (2015). A Reliability Study of Parent Belief Inventory (PRBI) - the Case of Albania. International Journal of Academic Research in Business and Social Sciences, 5 (4), 154-165. doi: 10.6007/IJARBSS/v5-i4/1547.

Evans, M. A., Fox, M., Cremaso, L. \& McKinnon, L. (2004). Beginning Reading: The Views of Parents and Teachers of Young Children. Journal of Educational Psychology, 96 (1), 130-141.

Franzen, M. D. (2013). Reliability and validity in neuropsychological assessment. New York: Springer Science \& Business Media.

Gonzalez, J. E., Taylor, A. B., Davis, M. J. \& Kim, M. (2013). Exploring the Underlying Factor Structure of the Parent Reading Belief Inventory (PRBI): Some Caveats. Early Education \& Development, 24 (2), 123-137. doi: 10.1080/10409289.2011.623651.

Gorsuch, R. L. (1983). Factor Analysis. Hillsdale, NJ: Erlbaum.

Horn, J. L. (1965). A rationale and lest for the number of factors in factor analysis. Psychometrica, 30, 179-185.

Husain, F., Chooa, J. C. S. \& Singh, M. K. M. (2011). Malaysian mothers' beliefs in developing emergent literacy through reading. Procedia - Social and Behavioral Sciences, 29, 846-855.

Iflazoglu Saban, A., Altinkamis, N. F. \& Deretarla Gul, E. (2018). Investigation of Parents' Early Literacy Beliefs in the Context of Turkey through the Parent Reading Belief Inventory (PRBI). European Journal of Educational Research, 7 (4), 985-997.

Jackson, D. A. (1993). Stopping rules in principal components analysis: a comparison of heuristical and statistical approaches. Ecology, 74 (8), 2204-2214. doi: 10.2307/1939574.

Johnson, T. P. (1998). Approaches to Equivalence in Cross- Cultural and Cross-National Survey Research. ZUMANachrichten Spezial, 3, 2-40.

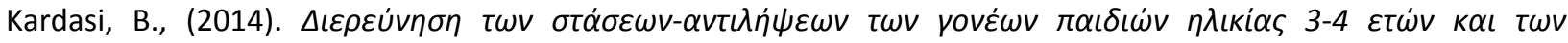

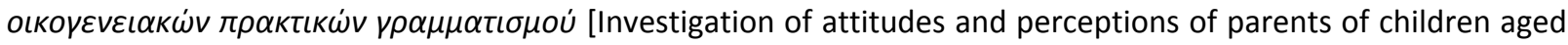
3-4 years old and of family literacy practices], [theses]. Patras: University of Patras.

Lynch, J., Anderson, J., Anderson, A. \& Shapiro, J. (2006). Parent's beliefs about young children's literacy development and parents' literacy behaviors. Reading Psychology, 27, 1-20.

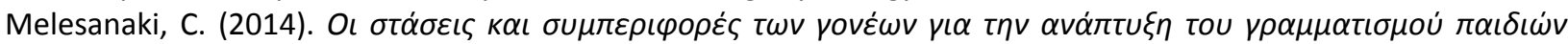

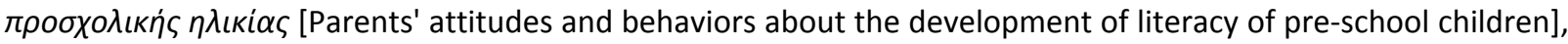
[theses]. Heraklion: University of Crete.

Mullis, I. V. S., Martin, M. O., Foy, P. \& Drucker, K. T. (2012). PIRLS 2011 international results in reading. In PIRLS 2016 Assessment Framework (2 ${ }^{\text {nd }}$ ed.). TIMSS \& PIRLS International Study Center, Lynch School of Education, Boston College.

O'Connor, B. P. (2000). SPSS and SAS programs for determining the number of components using parallel analysis and Velicer's MAP test. Behavior Research Methods, Instruments, \& Computers, 32 (3), 396-402.

Pett, M. A., Lackey, N. R. \& Sullivan, J. J. (2003). Making Sense of Factor Analysis: The Use of Factor Analysis for Instrument Development in Health Care Research. Thousand Oaks, CA: Sage.

Purcell-Gates, V. (1996). Stories, coupons and the TV Guide: Relationships between home literacy experiences and emergent literacy knowledge. Reading Research Quarterly, 31 (4), 406-428.

Radisic, J. \& Seva, N. (2013). Exploring the Factor Structure of the Parent Reading Belief Inventory (PRBI): Example of Serbia. Psihologija, 46 (3), 315-330. doi: 102298/PSI130716007R.

Rodriguez, B., Hammer, C. \& Lawrence, F. (2009). Parent Reading Belief Inventory: Reliability and Validity with a Sample of Mexican American Mothers. Early Education Development, 20 (5), 826-844. doi: 10.1080/10409280802581276.

Rowe, M. L. \& Casillas, A. (2010). Parental goals and talk with toddlers. Infant and Child Development, 20, $475-494$. doi: 10.1002/icd.709.

Sigel, I. E. \& McGillicuddy-De Lisi, A. V. (2002). Parent Beliefs are Cognitions: The Dynamic Belief Systems Model. In M. H. Bornstein (Ed.), Handbook of Parenting. Being and Becoming Parent (pp. 485-508). NJ: Lawrence Erlbaum Associates.

Simsek Cetin, O., Bay, D. N. \& Alisinanoglu, F. (2014). Ebeveyn okuma inanc olcegi'nin Turkceye uyarlama calismasi (Turkish adaptation study of the Parent Belief Inventory). Electronic Turkish Studies, 9 (2), 1441-1458.

Sonnenschein, S., Baker, L., Serpell, R., Scher, D., Goddard-Truitt, V. \& Munsterman, K. (1997). Parental Beliefs about ways to Help Children Learn: The Impact of an entertainment or a Skills Perspective. Early Child Development and Care, 127/128, 111-118. doi: 10.1080/0300443971270109.

Sonnenschein, S., Baker, L., Serpell, R. \& Schmidt, D. (2000). Reading is a source of entertainment: The importance of the home perspective for children's literacy development. In K. A. Roskos \& J. F. Christie (Eds.), Play and literacy in early childhood: Research from multiple perspectives (pp. 107-124). NJ: Lawrence Erlbaum.

Stone, C. A., Silliman, E. R., Ehren, B. J. \& Wallach G. P. (2014). Handbook of Language \& Literacy: Development and Disorders ( $2^{\text {nd }}$ ed.). NY: Guilford Publications. 
Tabachnick, B. G. \& Fidell, L. S. (2007). Using multivariate statistics (5th ed.). Boston, MA: Pearson.

Teale, W. H. (1986). Home background and young children's literacy learning. In W. H. Teale \& E. Sulzby (Eds.), Emergent literacy: Writing and reading (pp. 173-206). Norwood, NJ: Ablex.

Teale, W. H. \& Sulzby, E. (1986). Emergent Literacy as a perspective for examining how young children become writers and readers. In B. H. Wasic (Ed.), Handbook of Family Literacy (pp. 7-25). New York: Routledge.

Teale, W. H. \& Sulzby, E. (1989). Emergent literacy: New perspectives. In D. S. Strickland \& L. M. Morrow (Eds.), Emerging Literacy: Young children learn to read and write (pp. 1-15). Newark, DE: International Reading Association.

Turkay, F. \& Iflazoglu, Saban, A. (2011). The Parent reading belief inventory: a study of reliability and validity. Paper presented at the $25^{\text {th }}$ National Conference on Turkish Linguistics, Cukurova University, Turkey.

Weigel, D., Martin, S. \& Bennett, K. (2006). Mothers' literacy beliefs: Connections with the Home Literacy Environment and Pre-School Children's Literacy Development. Journal of Early Childhood Literacy, 6 (2), $191-211$. doi: $10.1177 / 1468798406066444$.

Whitehurst, G. J. \& Lonigan, C. J. (1998). Child development and emergent literacy. Child development, 69, 848872. doi: $10.2307 / 1132208$.

Wood, N. D., Akloubou Gnonhosou, D. C. \& Bowling, J. W. (2015). Combining parallel and exploratory factor analysis in identifying relationship scales in secondary data. Marriage \& family review, 51 (5), 385-395. doi: 10.1080/01494929.2015.1059785.

Wu, C. C. \& Honig, A. S. (2010). Taiwanese mothers' beliefs about reading aloud with preschoolers: Findings from the Parent Reading Belief Inventory. Early Child Development and Care, 180 (5), 647-669. doi: 10.1080/03004430802221449. 